\title{
Case Study for Product Development Innovation Based on Design Thinking Approach, Demonstrated by Smart Furniture Project
}

\author{
Emma Lógó1, Vanda Orbulov* \\ ${ }^{1}$ Department of Ergonomics and Psychology, Faculty of Economics and Social Sciences, Budapest University of Technology and \\ Economics, Múegyetem rakpart 3. H-1111 Budapest, Hungary \\ * Corresponding author, e-mail: orbulov.vanda@erg.bme.hu
}

Received: 07 October 2020, Accepted: 30 November 2020, Published online: 09 December 2020

\begin{abstract}
The paper intends to demonstrate the functional role and application of methods provided by the design thinking mindset when the team should create an innovative product design concept in a multidiscipline environment. First, the essential description and features of a design thinking mindset are significant for the discussed topic are introduced, along with defining the specialties and expected output of the featured smart furniture project. Second, after a clear view of the applicable mindset, the paper aims to sketch the project scope by reasoning the applied design thinking methods and highlighting the product design process's challenges. Finally, the article makes a definite conclusion for demonstrating the design thinking mindset's experienced application, completed by the detailed evaluation of research questions based on empirical data. The purpose of the article is, on the one hand, to highlight the role and significance of the design thinking mindset in an innovative project. On the other hand, emphasizing that well-chosen methods in the right team composition with a well-defined problem already carries the key to the solution. The paper's novelty is the detailed practical description confirmed by concrete results of successfully applied methods needed to design a clear vision and scope for a multidiscipline team by design thinking mindset.
\end{abstract}

Keywords

design thinking, customer experience, problem solving, design practice, empathy, user centered design, product design

\section{Introduction and aims}

The paper intends to introduce a real-life project. A dedicated team of innovatively designed smart furniture is assumed to be more competitive from three diverse aspects: a design thinking approach for the innovation [1], a narrative of smart furniture creation, and summarizes some new insights of a unique design process. Moreover, the reason for this is that creating something new is not only manifest in the outcome of the process but simultaneously in the learning and understanding of a complex problem during the design process. After reasoning the application of the design thinking aspect, the expected advantages for product development are summarized by research questions. Understanding and definition of problems from a customer-aspect are critical factors in the research [2]. The application of framing and the unusual, innovative process intended to point out the usability, effectiveness, and competitiveness of the applied mindset $[3,4]$. The innovative approach should bring a novel learning process not only for all members of the design team but also for stakeholders in a broad context covering the whole process. Smart products are often defined as products - regularly completed by services - having digitalized solutions as leading attributes or, smart products have to be considered in the context of their (typically smart) environment [5]. Authors tend to reinterpret the definition of smart products from a product development perspective by identifying the smart attributive as a basis of the development process, besides the optional digital features. Smart products are also known as intelligent products [6] or "a physical and information-based representation of a product", that able to communicate effectively with its environment [7]. According to the authors, a smart product defines a conscious development process's valuable solution or output, where decisions are made based on customers' needs and feedback. Authors went beyond the smartness characters as awareness, 
connectivity, actuation, and dynamism [8]. In the paper, smart attributes are not necessarily connected to any digital, intelligent, tangible product or features but to the smart process that aimed to create the needed value for the customers and integrate new technologies in the furniture industry. The validation results for the applied approach in product development involving external stakeholders are also introduced in the paper, aiming to highlight the assumed advantages of the design thinking approach against traditional product development output.

\subsection{Combinations of tradition and innovation}

The meeting of the traditional and innovative elements arose from three crucial aspects. First, the "smart office for the future generation" project aims to develop innovative furniture and furniture-type products that combine traditional furniture manufacturing technologies with the latest digital technologies. The designed furniture is to find answers to the office use habits of the generation Y, including ergonomic, psychological, and functional needs of the work and other activities to be performed there (maybe including new technologies, new materials, or new production systems). The preferred innovative development process with the design thinking approach will allow the design of objects to be dynamically adaptable to the user's needs, providing further contributions and advantages. Second, besides introducing the experienced impacts of the involved design thinking mindset in detail, the authors propose the shreds of evidence of reinterpreting the traditional definition of the attributive smart during the development process. Finally, the project was formed as a prototype experimental sample office offering a validation area for demonstrating the difference between the output of a traditional designing process and the applied innovative one.

\subsection{Overlapping project phases}

Smart furniture project consisted of two hubs. The first hub aimed at an innovative development process, including a design strategy, providing a user-centered approach. The second hub has a strong technical focus on the addressed possibilities of using materials and semi-finished products that are less common in the furniture industry but can be machined with traditional and computer-controlled woodworking machines. Two hubs are complementary and overlapping: technological feasibility and implementation should be built on a stable exploratory phase, ensured the correct definition of the problem, the understanding of user needs, available resources, and influencing circumstances. The paper focuses on the first hub introducing a new method by applied the design thinking aspect and reinterpreted the conventional definitions and processes.

\section{Review of literature on innovative processes in the design}

Design is a creative problem-solving, creative process, and decision-making that requires both artistic and scientific creativity. Design is not one way of thinking: it is a mix of different kinds of thinking [9]. Paper defined all the stakeholders were involved in the product development process as a design team. The design team decided to create products delightful and enjoyable, which means according to Norman [2] "that not only must the requirements of engineering, manufacturing, and ergonomics be satisfied, but attention must be paid to the entire experience, which means the aesthetic of form and the quality of interaction". A design thinking mindset is a very topical issue today. However, the literature has mostly gone beyond defining design in terms of industrial design, manufacturing of products, and product design issues, but is still careful to delimit the subject's entire field. According to Brown, thinking like a designer can transform the way team develops products, services, processes - and even strategy [10]. Cooper [11] highlighted a historical background of design research from its start in the 1960s and has got a broad role and application within innovation, throughout society and industry [11]. Nowadays, design has probably become a complicated way of thinking and guiding principles that affect all life situations [12]. Cross [13], according to three perspectives compared to one in the sciences, the meaning of design was determined to the humanities and design. After had been contrasted the sciences, the humanities, and design under each aspect, Cross could come closer to highlight the main essence of design: the appropriate methods of design are modeling, pattern-formation, synthesis, while the values of design are practicality, ingenuity, empathy, and concern for "appropriateness" [13]. Design thinking is an inspiring new paradigm for dealing with problems in many professions, especially in IT and business [9]. The approach is a more creative and user-centered approach to problem-solving than traditional design methods [14]. The three-years-long smart furniture project offered extraordinary opportunities for enforcing the appropriate methods throughout the whole development process. Although many of the activities that designers do are relatively extensive, and thus it is irrelevant to claim 
these as limited to design thinking, some of these activities have been adopted to the design disciplines in ways that could be valuable for other fields [9].

\subsection{Challenge on multidisciplinary}

Design thinking is an approach to address wicked problems with multidisciplinary and cross-functional innovation teams [1]. The collaboration of different disciplines makes success for the project. Individuals have to collaborate closely for designing a unified whole [15]: foreign environments and people from different cultures with disparate ways of thinking and working significantly increase the uncertainty. Unless having a deep mindset for multidiscipline collaboration, deadlines and results would not have been realized successfully. Design thinking mindset engaged strongly on integrative workflow containing as many diverse professional and human aspects as many ones needed and profitable for the project. The designer creates solutions from the customer's perspective, knows the users, and seeks answers to their' real needs. In a multidiscipline environment, diverse approaches and experiences may better impact designing from the customer's aspect. The multidisciplinary and cross-institutional team investigated the design thinking mindset in its holistic dimensions. With backgrounds in engineering, design, legal, ergonomics and social sciences, team members strive understand of the underlying principles and, consequently, how and why the innovation method of design thinking methods in this project works and fails. Team composition can be reasoned by its diverse nature, necessary for applying professional added values, and resulting multidisciplinary background. Members are all experts, were convinced that in the significant part of the process experienced designers bring success, expert designers are solution-focused, not problem-focused [16]. The aim was not only to develop the right product but also to capitalize on the application of design thinking methods primarily aimed at coping with challenges posed by multidisciplinary teams. The added value stems from collaborative teamwork; the learning process is profitable for future developments.

\subsection{Cross-institutional structure}

However, in theory, definitions and key circumstances should be fixed as soon as possible during the project planning. The issue was the point in our case: using a design thinking approach to steer the project into a concrete channel, managing very diverse professionals in a frame of a cross-institutional project. The application of the design thinking mindset also had successful consequences at other relevant educational institutes, between Stanford University and Hasso Plattner Institute in 2018, where a design thinking research program and its investigation of the technical, economic, and human factors was the logical consequence of merely teaching the design thinking method. Researchers at both institutions, with various types of backgrounds in disciplines such as engineering, humanities, neurology, or economics, examine how the innovative processes that originate in small, multidisciplinary teams can be improved and further developed [17]. In our case, a technical focused institute, and an art-design-orientation one had current cooperation. The multidiscipline team combined two education institutes' professionals in a smart furniture project: a technical focused one and an art-design oriented one. Artistic creativity is expressive and emotional, and scientific creativity is goal-oriented and disciplined [12]. Artistic and scientific creativities bring together many different disciplines in creative and innovative ways, having relevant impact on each other, completing the various professional presence in the working team.

\subsection{Human-centered approach}

Designers' activity is a specific synthesis of artistic, economic, and engineering knowledge. It also encompasses the complex, human aspects of form and space creation, assuming broad connections. In addition to aesthetics, integrating the product into the economic, social, cultural, and technological environment is essential. According to László Moholy-Nagy, the ultimate goal of design is the human. A design thinking mindset is a human-centered approach, innovative problem solving, focusing on human aspects covering the human identities themselves and the social, environmental, and economic factors in a longterm period. During the whole process of designing, the design team applied the approach of human-centered design (furthermore: HCD), which is a mindset that puts human needs, capabilities, and behavior first, then designs the accommodate those needs, capabilities, and ways of behaving [2].

\subsection{Linear process vs. design process}

Projects are different however, all the ones have similarities for what best practices, rich and essential recommendations are widely offered by relevant international and professional organizations [18]. A project is organized to achieve a pre-defined objective, within a specific 
time, quality, and budget constraints, clearly defined with responsibilities and milestones [17]. Whereas most of the pre-defined objectives, expectations concerned the scheduling and budget were not specified for the design team, the team decided to apply the design thinking approach's methodologies. Design thinking can achieve results even though its architecture differs from the linear, milestone-based processes typical of business activities [10]. The design process can describe metaphorically as a system of spaces rather than a pre-defined series of orderly steps. It can also be interpreted as a creative humancentered discovery process followed by iterative prototyping cycles, testing and refinement [10]. The design is more than just the design of the form; it also covers thinking about processes. The process includes products' application, the development of the plan, the execution of the production, and the realized result's life cycle. A design thinking mindset was followed; after analyzing the existing practical approaches, the design team created a novel methodology adapted to the project. The design process concerning the smart furniture project starts with creating the design concept, after which the team follows the activities of the applied design process selected after careful consideration.

\subsection{Key Design Concepts and processes}

Before listing processes in chronological order, the design process's definition, exceptionally diverse from design methods, should be defined. Design methods are mainly techniques, rules, or ways of acting by applying the design thinking mindset. Design processes were listed as individual design methods forming phases in real action. Design processes can be linear or circular, or even a mix of them. Processes have differed in several respects, so in the numbers and flags of phases.

\subsubsection{Science of the artificial}

The design team was highly impressed by Simon's statements [19] in 1969 as an early design process model. Simon, as artificial intelligence and cognitive science researcher, established the science of design. He presented a model of seven stages: definition, researching, ideation, prototyping, choosing, implementation, and learning [19]. Within the model's seven phases, designers can frame problems, create more and more ideas, and choose the best solutions. His model differs from the linear, milestone-based processes. Thus, it became applicable to flexible product development processes.

\subsubsection{Model of Iterative Cycle of Human-Centered Design}

The British Design Council first introduced the doublediamond model of the design in 2005. The model focuses on finding the right problem and finding the right solutions for fulfilling human needs simultaneously. The two diamonds represent a process of exploring an issue widely or deeply entitled as divergent thinking and then taking focused action as convergent thinking. Researchers were also aware that there is also an opportunity for HCD to be adopted outside the traditional design field in strategic innovation processes [20]. After researchers have been inspired by multi-layer models to identify different types of human needs and aspirations that inform a design and innovation process, they introduced a new, four-layer model of needs and aspirations: human Needs and Aspirations for application in a Design and Innovation process (using the acronym 'NADI'). This model's unique feature is that the term aspiration not just focuses on immediate needs but also includes longer-term hopes, desires, and ambitions [20]. This mindset is advantageous in a case where the design team needs to meet future needs, as in our project. The Iterative Cycle of Human-Centered Design was created and published by Norman [2] in 1988 as follows: observation, ideation, prototyping, and testing. Activities named as elements are repeated from time to time, getting closer to the best solution to the explored and defined problem definitively from a human aspect.

\subsubsection{Triangular-shaped process}

The founder of the innovation and design firm IDEO stated in 2008 that design projects should ultimately pass through three spaces labeled as inspiration for the circumstances, ideation for the process of generating, developing and testing ideas leading to solutions, and implementation for the charting of a path to market [10]. Projects loop back through these spaces. To follow a detailed and well-designed journey throughout the process, the design team preferred to find a model providing more steps. The model focuses on developments that are technologically feasible and economically viable for humans, highlighting the importance of empathy.

\subsubsection{Impactful user experiences}

Design thinking focuses ongoing broader for "building up" the ideas by understanding our users. Design thinking differs from traditional analytic user-centered design methods by focusing on "going broad" at the initial design stages instead of the analytical approaches directing narrowing 
the design choices [14]. Critical attributes of design thinking are the open mindset, the collaboration, and empathy, according to Baeck and Gremett. Their design process's main phases are definition, inspiration, ideation, prototyping, and getting feedback from users as testing [14].

\subsubsection{Model of the Hasso Plattner Institute}

Model of the Hasso Plattner Institute (Furthermore: HPI) is contained by the Design Thinking Bootcamp Bootleg issued in 2018 by Hasso Plattner Institute of Design School at Stanford [21]. The process's phases are the following: empathizing, definition, ideation, prototyping, testing, including refining and implementation [21].

\subsubsection{Overview of examined models}

The overview of the examined models is introduced in a structured and transparent form in Table 1.

\section{Research questions}

The construction and technical implementation of smart furniture requires a pragmatic attitude. Solving the problem requires a comprehensive concept for the current project. In creating the concept, participants relied on the design thinking approach, among others, because of its holistic nature.

Research questions cover the three main fields suspected to achieve relevant findings and further developments. The first field to be improved is the innovation's design thinking approach. The design thinking-led process makes the problem definition and the team collaboration more impactful, significantly affecting the development process's final output. The smart attributes' purpose was reinterpreted into a smart product development process as a research question as to the second field.

Table 1 Design thinking processes examined by the authors

\begin{tabular}{|c|c|c|c|c|}
\hline 1969 & 1988 & 2008 & 2011 & 2018 \\
\hline$\stackrel{\Xi}{\stackrel{0}{\Xi}}$ & 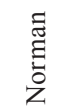 & 客 & 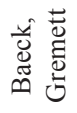 & $\overline{\underline{I}}$ \\
\hline D & \multirow{2}{*}{$\mathrm{O}$} & \multirow{2}{*}{ In } & D & $E$ \\
\hline $\mathrm{R}$ & & & In & $\mathrm{D}$ \\
\hline Id & Id & Id & Id & Id \\
\hline $\mathrm{P}$ & $\mathrm{P}$ & \multirow{2}{*}{$\mathrm{Im}$} & $\mathrm{P}$ & $\mathrm{P}$ \\
\hline $\mathrm{Im}$ & $\mathrm{T}$ & & $\mathrm{U}$ & $\mathrm{T}$ \\
\hline
\end{tabular}

$\mathrm{D}=$ Definition, $\mathrm{E}=$ Emphatizing, $\mathrm{F}=$ Framing, $\mathrm{Id}=$ Ideation, $\mathrm{Im}=$ Implementation, $\mathrm{In}=$ Inspiration, $\mathrm{O}=$ Observation,

$\mathrm{P}=$ Prototyping, $\mathrm{R}=$ Researching, $\mathrm{T}=$ Test, $\mathrm{U}=$ User feedback
The question related is the validation of the reinterpretation of the smart attributes by testers stating smartness goes beyond the appearance of digitizing elements in the case of designed products. The third research question was related to the learning process provided by the design thinking approach. A relevant, tangible contribution of the design thinking approach was created for all the stakeholders defined clearly as added value.

Authors designed an experiment to combine these challenging fields, the user-centered design with the opportunity-driven technology-based innovation, based on user perceptions. Besides, our intention for answering the research questions was twofold; firstly, to explore in a controlled environment how innovative outcomes can be created for the particular situation, and secondly, how new knowledge or a deeper understanding of a traditional product design problem can be gained by the unique juxtaposition of interpreting new technologies and designing new products.

\section{Presenting concept, process, and methods}

For providing a comprehensive view, professional reasons for choosing the concept, process, and methods are complemented by offering the achieved results. Reflects for research questions are detailed in Section 5. After recognizing the methods and their relevant outputs.

The smart furniture design team consisted of two parts. The core team consisted of experts and researchers, an environmental psychologist, design thinking expert, ergonomist, interior designer, technology expert, and a generation researcher. The involved student team significantly supported the workflow by contributing essentially to all the concluded methods. Undergraduate and graduate students worked individually and in teamwork, latter realized by applying the design sprint methodology or a so-called hybrid, user-experiences course. There were individual tasks for design assignments in a product design course and an interior design-themed space design course, also supported by the core team. The students received the same research materials as experts. Besides, the researchers held an orientation day where they presented the results in workshops.

\subsection{Simplicity-led design concept}

In this case, the concept was the basis and reference point of the design idea; it included fundamentals that the design team wanted to adhere to throughout the project. The main guidelines for the concept were clear intentions: the applicability of traditional furniture manufacturing processes and the integration of smart process, smart features into the 
office environment, praying primary attention to simplicity. These concept guidelines explicitly mean an inspiring, vibrant, harmonious, and balanced environment for generation Y, complete with a sense of simplicity. The priority of concise, concentrated form and the essence of the concept was that although the smart office tools and equipment represent a high technology level, they are effortless to use. The design team intended to design everyday things as smart office assets. As people are frustrated with everyday things, especially from the ever-increasing complexity also covering the extra required activities for updating, maintaining of all our belongings [2]. Friedman [22] pointed out designers' challenge that they find simplicity in artifacts and processes; on the other end, they find complex adaptive systems, networks, and processes [22]. Digital systems and digital solutions need the complexity increasingly need customers to require a simple way of use and high quality. As highlighted in the first section, the smart feature was not defined exclusively as an integrated digitalized solution of the products, but the smart characteristic impacting the whole designing process. According to Mollerup [23], as the world becomes increasingly complex, simplicity frequently becomes in demand. Simplicity depends on customers' experience, knowledge, understanding, and skills [23]. Three aspects of the design were recognized during the designing process: simplicity for comfort, simplicity for pleasure, and simplicity for conscience. Simplicity is not equal to simple; that is an essential point for fixing the concept. As stated by Norman [24] stated that the good life is complicated, rich, and rewarding in the case of if it is understandable, sensible, and meaningful. Designers should soften complexity for an "edible" and understandable form for users avoiding confusion. Complexity is not a problem, but the design should manage it well [24].

\subsection{The design process of smart furniture}

Based on the synthesis of relevant literature and smart furniture's unique needs detailed in Section 2.5, we have constructed our design process shown in Table 2. The design-thinking framework follows a complete flow of phases understanding, exploring, and materializing.

Since the smart furniture project's essence was not linked to one dedicated model, explained on a professional basis, we followed the general model compiled, based on the process models examined. The smart furniture project's applied methods are presented in the order of the process elements presented as part of Table 2, rightmost column (Lógó and Orbulov in present study).
Table 2 Design thinking processes examined by the authors

\begin{tabular}{|c|c|c|c|c|c|}
\hline 1969 & 1988 & 2008 & 2011 & 2018 & 2020 \\
\hline 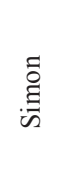 & $\begin{array}{l}\text { :ี } \\
\text { Ẽ } \\
\text { Z }\end{array}$ & 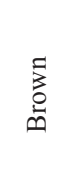 & 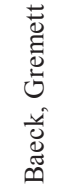 & $\overline{\underline{I}}$ & 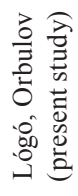 \\
\hline D & \multirow{2}{*}{$\mathrm{O}$} & \multirow{2}{*}{ In } & D & $\mathrm{E}$ & $\mathrm{D}, \mathrm{F}$ \\
\hline $\mathrm{R}$ & & & In & D & $\mathrm{O}$ \\
\hline Id & Id & Id & Id & Id & Id \\
\hline $\mathrm{P}$ & $\mathrm{P}$ & \multirow{2}{*}{$\mathrm{Im}$} & $\mathrm{P}$ & $\mathrm{P}$ & $\mathrm{P}$ \\
\hline $\mathrm{Im}$ & $\mathrm{T}$ & & U & $\mathrm{T}$ & $\mathrm{T}$ \\
\hline
\end{tabular}

$\mathrm{D}=$ Definition, $\mathrm{E}=$ Emphatizing, $\mathrm{F}=$ Framing, $\mathrm{Id}=$ Ideation,

$\mathrm{Im}=$ Implementation, $\mathrm{In}=$ Inspiration, $\mathrm{O}=$ Observation,

$\mathrm{P}=$ Prototyping, $\mathrm{R}=$ Researching, $\mathrm{T}=$ Test, $\mathrm{U}=$ User feedback

\subsubsection{The phase of definition, framing}

Our essential goal is to gather tools for understanding that can help explore the problem's context in this phase. Norman stated that "good design starts with an understanding of psychology and technology" [2] studies were made before the principles: the right design could be totally integrated into practice. A well-defined problem already carries the key to the solution. Design problems are regarded to be ill-defined. Another source of complexity is that design problems can require creativity to some extent, and it has a variety of potential solutions that more or less satisfy different criteria [25]. Impressive design behavior is based not on extensive problem analysis, but adequate 'problem scoping' and a focused or directed approach to gathering problem information and prioritizing criteria [16]. Thus, the starting point of designing is the problem itself, i.e., we do not have a ready answer or ready design. Designers have been dealing with open, complex problems. The challenge of dealing with these open, complex problems leads to a particular interest in the ways designers create 'frames', and how design organizations deal with frames in their field of practice [9]. Like all designers, the real problem should have been found before solving any of them. The design team did not design smart furniture, but an environment that creates a comfortable and safe living space for this generation for work and related activities. All of the team designers were also able to examine the problems from the user's perspective. Moreover, Dorst [26] described how the coevolutionary interpretation of design thinking has developed from descriptive accounts of how designers think of innovation and reframing interactive problems [26]. The designer's decisions are examined and justified from several perspectives. 
Design practices have been developed in response to an exact need. Dorst [9] highlighted that, if designers like to create a value for users, the future product to be created and the working principle to be fixed is a specific value. Framing should be a useful solution if designer team face open and complicated problem situation. After Schön's theory on reflection-in-action was published in 1983, design research got a new impulse by challenging the leading rationalist paradigm [27]. Reflection-in-action can be understood as "knowing is in our actions", along with Schön's wording [27]. Beyond dispute, Schön's theories are vital for understanding the point of design practice, but researchers also highlighted a suspected problem by adopting his principles being especially valid for individual designing, into teams and organizations. The question was whether Schön's theories are applicable for teams and organizations, above all concerning the core of design practice: frame creation [15]. After studying the process of reflection-in-action in the context of the design team empirically, researchers stated that reframing is amplified for multidisciplinary teams, compared to an individual. Additionally, it is an iterative and socially constituted process [15]. The project aimed to answer a social and economic problem, the significance of which is not yet directly felt. Framing was applied term for creating of a new viewpoint, how designers can handle a problem, or a problematic situation tend to be solved [27]. Framing can also be explained as a way of a problem is interpreted, and a solution is looked for [15], or the way of structure and formulate the problem [16]. Our research also intends to explore the social dimension of the collaborative design from the perspective of Schön's reflective practice [27, 28]. However, the practice was determined as an ongoing activity [27], we apply framing in the early phase of the designing process according to our conviction, also based on former studies and research [3, 29]. The design team aimed to bring closer issues to be perceived far from the central paradox. These issues became triggers for creating a new framework allowing one to approach the core open and complex problem in a novel and unexpected way, as Dorst described [9]. From this perspective, a clear trend- and market research was conducted for bringing new external aspects into the designing process. Market research and design research are complementary, but each has a different focus. From the designer perspective, we highlighted the application of qualitative observations, mostly focusing on the question: how the future users do their activities complementing strongly by environmental factors, while our market analysis attracted the large-scale quantitative studies like surveys and questionnaires, trying to find the answer: what factors entice the customers to purchase our products [2].

\section{Trend-and market research}

Data collections were done by in-house designers supported by professionals in related fields. Data for trend analysis covered several crucial perspectives: the changing labor market, corporate forms and work organization, the office as a space of communication, aspects of employer and one of the employees completed by an outlook for the generations, office design and space organization, completed by a healthy sustainability perspective. Market research contained interviews and field research. In the part of the market research, 24 face-to-face interviews were conducted. For an in-depth understanding, it is essential to ask how and what to invite people who use and provide services. In one-half of the personal interviews, we interviewed office workers who mostly perform administrative tasks. We talked about their official duties, communication, devices applied, and the office environment with them. In the other half of the interviews, decision-makers were interviewed about what aspects they shape the office environment for their employees. Moreover, interior designers informed the team about how they are involved in procurement, office design processes, and how professional aspects can be mainstreamed in projects. Interviews were followed by field research in two office buildings and customer attitude surveys.

\subsubsection{Phase of observation}

Observation of interesting segments and future users is crucial. It belongs to the deep understanding because people are often unaware of their true needs and even unaware of their difficulties. Design research differs from scientists' research. It happens directly at the customers themselves, for having clear maps about their needs, interests, motives, and understanding the real situations they encounter, not some pure isolated experiences [2]. During the observation phase empathy had a vital role. Empathy and design are in powerful connection, Cross defined empathy as a critical value of design in each culture [13]. In recent years a mindset, entitled empathic design has developed as demonstrating the main focus of the design process: the user. Moreover, design empathy is considered being taken to enhanced by several types of techniques such as research techniques for establishing contact between users and designers, techniques for communicating findings of 
user studies to design teams like the storytelling, or the ideation techniques to evoke a designer's own experiences in a field relevant to the user [30]. By taking a "people first" approach, design thinkers can imagine constitutionally desirable solutions and meet definite hidden needs [10].

\section{Field research}

The design team conducted field research in two multinational companies' office building to discover future users directly in their environment. Employees of the observed companies belong to the IT sector, but daily tasks are different. Many aspects were examined and recorded by the field research, like the feelings, impressions, physical space, space use, communications, teams, team cooperation, activities, health, air, and light completed by surprising issues. In the first company with around 500 employees, 250 software developers and their working conditions were focused. They work according to the scrum methodology, so it is typical for 8-10 people to work together, separated. The spaces were slightly separated (with cabinets, plants). According to recent projects, there are many moves due to changing team lineups - that is why rearrangement of spaces is common. There are many spaces for working together (meeting rooms, teamwork rooms, chat rooms, sofas, armchair islands), writable walls everywhere. The company's cornerstone is innovation and digitalization; therefore, the latest trends can be seen in the work environment. It is thus interesting for research because we can get an idea of a company's environment that where adequate resources and knowledge are also available to be productive and convenient to create an environment. After evaluating all the listed aspects for field research, researchers concluded that relaxes, personal conversations, and employees at work can solve coworking. In the second observed company, the working conditions of almost 400 employees were observed; they have just moved to the new offices before the timing of their field research. People work in sparsely separated, large spaces, with meeting rooms of different sizes and relaxation rooms to help with the work. Researchers were also able to gain insight into the environment of administrative, HR, and managerial jobs. An exciting picture was experienced in creating an office environment where more cohesive and traditional office work is typical, yet initiatives emerge to create an innovative and comfortable work environment. After the observation phase was covered by field research, team members used the data gathered to collect insights. The team organized the observations and made parallels across users' experiences. The design team identified the common pain points and defined unmet user needs and outputs defined in the definition phase.

\section{Customer survey}

In parallel with field research design, team members prepared an online user survey involving 65 respondents from the targeted $\mathrm{Y}$ generation. First, the team defined the main activities at work based on the definition and observation phase's outputs, completed by the 24 face-to-face interviews detailed in Section 6.1.1. Data were collected through the survey via choice-based questions using a maximum difference scaling format. In this format, the users were exposed to sets of motivations and selected the one that best described their feelings and least described their feelings. The aim was to have a bright picture of feelings associated with a smart office they desire to work in, tailored to the former identified activities. Besides, the respondents provided the key preferred feeling they desire to have during the main activities at work; they also offered their vision about smart attributes.

\subsubsection{Phase of ideation}

In this phase, team members worked together tightly and sketched out many different ideas. This phase can be defined as the visualization of the insights. As respecting the advantages of Osborn's brainstorming in 1953 [31], the design team transformed the traditional brainstorming activity to recognize the possibility of a better and faster way for ideation. Thus, the team questioned the effectiveness of brainstorming in terms of usable ideas: not the ideas that were needed in the workshop proved to be feasible. Individual ideas proved to be better than group ideas. This may be because a participant does not have enough time to think carefully about the idea. Another important aspect is that some people perform better in the time constraint [32]. For the phase of ideation design team applied a modified version of the design sprint method [32] within a shorter period dedicated primarily for the ideation phase. The team applied the first three steps of the design sprint, posed the collection, structure, and priorities of ideas as a problem: map, sketch, and decide. The design sprint was highly efficient and brought out everyone's best contributions to the team by creating 455 ideas or statements.

\section{Affinity diagram}

The design team defined an affinity diagram as a method that helps teams collaboratively analyze research findings and ideas from the ideation phase is affinity diagramming. 
The method is highly impressive because it can create a single view of the statements out of hundreds of individual data [8]. Since they had many ideas on the first day of the individual design sprint, they should be transparent for future steps and drive design insight. The affinity diagram method allowed members to organize large sets of ideas into distinct clusters, within a workshop activity, as the second sprint day. In the smart office project, 455 statements were listed for the team on the first day. The next day, sorting was followed by summarizing 8 categories, decreasing the relevant and feasible ideas belonging to categories, and defining the priorities on the last day. Priorities were determined to have been identified by having design team members assign a finite set of points to those they think are important and need to be fixed. Usability testing concluded that involving stakeholders in all the design process phases has a significant, useful influence on the final result from the user's perspective. It was instrumental in educating other team members, involving them in design, building consensus, increasing sensitivity to usability issues, getting them involved in taking notes, sorting them, and discussing them rather than protecting them from these processes.

\subsubsection{Phase of prototyping}

We made special attention to prototyping's phase because in many cases, the more finished a prototype seems, the less likely its creators will keep an eye on feedbacks [10]. Prototypes help us choose the solutions, but at the same time, also tools for intensive development. This phase's goal was to understand what components of the team's ideas work and which do not. In this phase, the design team began to weigh the impact and feasibility of ideas through feedback on prototypes. To realize a high-fidelity prototype, the design team created an experimental smart office involving undergraduates and graduate students from both institutions. The design team spent one day for the short-term simulation prototyping referred to as the design sprint method and profited in the ideation phase. The more time the team spends preparing the prototypes, the more its members insist on them, disrupting the acceptance of optional negative feedback. First, a visual reflection was designed as preparation by creating a detailed script for the movie. After the unreal tangible decoration has been made, scenes were filmed. Reason for simple decoration instead of making the real version is that the idea reveals sooner whether it is worth investing more energy if we present only one illusion to the test subjects [32]. The prototype seemed to be real, as expecting real feedbacks from testers. The design team recognized in time: the project is not just about physical goods but also the feeling of well-being, the satisfaction of the stable working performance, the opportunity for effective teamwork with individual working, the appropriate work-life balance.

\section{Storytelling}

For realizing the prototype, the decoration was completed by a story according to a script, playing scenes like a movie for the testers, demonstrating formed defined working activities. The question: the feelings they identify by watching the short films or the real drama to the specific activities? How close these feelings to the ones defined by the same respondents about the ideal smart office? The comparison was made after the testing phase for exploring all the possible contrasts.

\subsubsection{Phase of testing}

The testing phase incorporates three main sections: the experimental smart office, the smart feature, and the design thinking's contribution.

\section{Test of the experimental smart office}

The testing phase's fundamental question was if the solution meets users' needs and improved how they feel, think, or do their tasks. The test of prototypes happened in two ways, covering two groups of respondents. The first group of 65 respondents is the same as filling the online survey in the definition phase with identifying the operational activities completed by feelings for them. The group had an online recorded movie at the end of each scene; they had to answer questions about feelings linked to that. The difference between the former expressed ideas, feelings, and ones influenced by the prototyped version was the difference. The second group's members were the same as the one the design team visited as field research. Team asked for volunteers aged among the targeted $\mathrm{Y}$ generation, and the 34 respondents were invited to the experimental smart office test place, where the members of the design team played the scenes with recorded decoration. The answers given in the testing space were compared with the surveys filled by the 65 respondents in online form during the observation phase. A significant finding that could not observe any correlation between the answers of the two groups. However, the creation of products in the name of simplicity was in focus; some occasions were experienced by having a lack of understanding of right and possible application. 


\section{Test of the smart feature}

The testing questionnaire focused on the one hand on feedback about the experimental smart office concerning the former answers about expectations and feelings. On the other hand, testing extended the opinion of smart attributes. According to the respondents, smart features define a kind of an always available interconnection between objects, interfaces, physical and digital products to facilitate the workflow and support a better performance at work.

\section{Test of the design thinking's contribution}

To assess the usefulness and the optional contribution of the learning process offered by the design thinking mindset, the team prepared a face-to-face interview guide for all the stakeholders.

The team desired to assess in in-depth interviews whether this method had been used, even in part, repeatedly in a development project. In an innovative project or a project for redesigning? According to the answers, the contribution was relevant. In addition to the positive assessment, the approach has also been used in the redesign, which suggests that it is dedicated to innovative projects and works well in those cases.

\section{Discussion of findings}

The research was conducted from a process-oriented perspective. We gained new insights into a new way of thinking. Questions of the exploratory research were also determined by this aspect, reflected in the process of innovation. As referred to in Section 3, research questions were defined clearly; after having been concluded, the design process for the smart furniture product development results and findings were evaluated, completed by further needed analyses.

The first research question had a clear answer: the design thinking-led process made the problem definition and team collaboration more impactful, significantly affecting the development process's final output. The methods for problem-definition provided by the design thinking mindset proven to be more effective and flexible for the following reasons. Easily adaptable working flow for designers by its flexibility: the architecture differs from the linear, milestone-based processes are typical of business activities. During the whole process, the user-centered approach was kept in focus, involving them in all the phases, was as close to them as possible for discovering and answering the real problem. The design team identified the smart furniture as a problem that has to be solved, required the bring a broader context for exploring around at the same time. Like the financial and technical feasibility, all other aspects were handled as an equal component during the development process, so they did not have any priorities before.

As the second field, the smart attributives' purpose was successfully reinterpreted into a smart product development process, defined by the second research question. However, the linear and exclusive relation between the smart attribute and innovative process approach could not be determined; the definition of the word 'smart' goes beyond the need for digital solutions.

The third research question targeted a significant contribution to the learning process provided by the design thinking approach. The most relevant contribution of the design thinking approach was created by the wide range of methods for managing, especially the challenges posed by the team composition's multidisciplinary essence. Perspectives meet in team workshops. Working in a multidiscipline team can be a serious advantage if participants know that the workshop is also a process in which the participants' experience should be designed. As the design team planned and conducted the workshop well by involving all the stakeholders at the right time, the shared information supported and helped the development process moves forward.

\section{Conclusions, limitation}

The project had not covered the implementation phase of the smart furniture project, though, put into vision, results would have been the real consequence could be further developed, refined, and finalized before a transformation into a final product and entering the market. The next step is to examine in what areas, how we can use it in the ordering partner's corporate environment, and what supports or even inhibits the transformation. A significant result is that we could link perceptions between other skilled experts by design thinking and different creative methodologies, provide a kind of universal language and contact point, and use this synergy. They were able to combine proper knowledge and project purposes usefully. In the project, the degree of design freedom stayed very high, almost unending at the beginning of the process. The team itself could formulate the definition of smart furniture, so design thinking was employed to identify later critical areas from which development issues and specific problems were transformed. Another outstanding success was that the applied creative methodologies allowed groups at different levels of knowledge to work collectively, such as teachers, students, and additional market partners; the methodologies created synergies here as well. When the key areas emerged after the 
Affinity workshop, the methodologies were followed by a user-centered approach throughout the project. The process became agile at each later stage, involving and engaging users as a primary pattern, hoping that the project's end will be ergonomic, comfortable to use, and future-proof precious smart furniture items.

\section{References}

[1] Plattner, H., Meinel, C., Leifer, L. (eds.) "Design Thinking Research, Making Design Thinking Foundational", Springer, Cham, Switzerland, 2016.

https://doi.org/10.1007/978-3-319-19641-1

[2] Norman, D. "The design of everyday things", Basic Books, New York, NY, USA, 2013.

[3] Dorst, K. "Frame Innovation: Create New Thinking by Design", MIT Press, Cambridge, MA, USA, 2015.

[4] McDonnell, J. "Design roulette: A close examination of collaborative decision-making in design from the perspective of framing", Design Studies, 57, pp. 75-92, 2018.

https://doi.org/10.1016/j.destud.2018.03.001

[5] Mühlhäuser, M. "Smart Products: An Introduction", In: Mühlhäuser, M., Ferscha, A., Aitenbichler, E. (eds.) Constructing Ambient Intelligence, Springer, Berlin, Germany, 2008, pp. 158-164. https://doi.org/10.1007/978-3-540-85379-4_20

[6] Lenz, J., MacDonald, E., Harik, R., Wuest, T. "Optimizing smart manufacturing systems by extending the smart products paradigm to the beginning of life", Journal of Manufacturing Systems, 57, pp. 274-286, 2020.

https://doi.org/10.1016/j.jmsy.2020.10.001

[7] McFarlane, D., Sarma, S., Chirn, J. L., Wong, C. Y., Ashton, K. "Auto ID systems and intelligent manufacturing control", Engineering Applications of Artificial Intelligence, 16(4), pp. 365-376, 2003. https://doi.org/10.1016/S0952-1976(03)00077-0

[8] Holtzblatt, K., Beyer, H. "6 - The Affinity Diagram", In: Holtzblatt, K., Beyer, H. (eds.) Contextual Design, 2nd ed., Morgan Kaufmann, Boston, MA, USA, 2017, pp. 127-146. https://doi.org/10.1016/B978-0-12-800894-2.00006-5

[9] Dorst, K. "The core of 'design thinking' and its application", Design Studies, 32(6), pp. 521-532, 2011. https://doi.org/10.1016/j.destud.2011.07.006

[10] Brown, T. "Design Thinking", Harvard Business Review, 86(6), pp. 84-92, 2008.

[11] Cooper, R. "Design research - Its 50-year transformation", Design Studies, 65, pp. 6-17, 2019. https://doi.org/10.1016/j.destud.2019.10.002

[12] Géczy, N. "Design", Scolar, Budapest, Hungary, 2019.

[13] Cross, N. "Designerly ways of knowing", Design Studies, 3(4), pp. 221-227, 1982. https://doi.org/10.1016/0142-694X(82)90040-0

[14] Baeck, A., Gremett, P. "Design Thinking: Expanding UX Methods Beyond Designers", In Degen, H., Yuan, X. (eds.) UX Best Practices: How to Achieve More Impact with User Experience, McGraw-Hill Osborne Media, New York, NY, USA, 2011, pp. 229-250.

\section{Acknowledgment}

The research reported in this paper was supported by the "Smart office furniture for future generations" Program of the Ministry for National Economy in the frame of COMPETITIVE CENTRAL HUNGARY OPERATIONAL PROGRAM (VEKOP-2.2.1-16-2017-00007.)

[15] Stompff, G., Smulders, F., Henze, L. "Surprises are the benefits: reframing in multidisciplinary design teams", Design Studies, 47, pp. 187-214, 2016.

https://doi.org/10.1016/j.destud.2016.09.004

[16] Cross, N. "Expertise in design: an overview", Design Studies, 25(5), pp. $427-441,2004$.

https://doi.org/10.1016/j.destud.2004.06.002

[17] Barbosa, A. P. F. P. L., Salerno, M. S., Nascimento, P. T. de S., Albala, A., Maranzato, F. P., Tamoschus, D. "Configurations of project management practices to enhance the performance of open innovation R\&D projects", International Journal of Project Management. (Accepted for publication July 2020) (in press) https://doi.org/10.1016/j.ijproman.2020.06.005

[18] Project Management Institute "A Guide to the Project Management Body of Knowledge (PMBOK Guide)", 6th ed., Project Management Institute, Newtown Square, PA, USA, 2017.

[19] Simon, H. A. "The Sciences of the Artificial", MIT Press, Cambridge, MA, USA, 1996.

[20] van der Bijl-Brouwer, M., Dorst, K. "Advancing the strategic impact of human-centred design", Design Studies, 53, pp. 1-23, 2017. https://doi.org/10.1016/j.destud.2017.06.003

[21] Doorley, S., Holcomb, S., Klebahn, P., Segovia, K., Utley, J. "The Design Thinking Bootcamp Bootleg", Institute of Design at Stanford, Stanford, CA, USA, 2018. [online] Available at: https:// dschool.stanford.edu/resources/design-thinking-bootleg

[22] Friedman, K. "The Design Continuum-From Simplicity to Complex Systems", She Ji: The Journal of Design, Economics, and Innovation, 2(2), pp. 103-104, 2016.

https://doi.org/10.1016/j.sheji.2016.10.002

[23] Mollerup, P. "Simplicity: A Matter of Design", BIS Publishers, Amsterdam, The Netherlands, 2015.

[24] Norman, D. A. "Living with Complexity", MIT Press, Cambridge, MA, USA, 2010.

[25] Simon, H. A. "Problem Forming, Problem Finding and Problem Solving in Design", In: Collen, A., Gasparski, W. W. (eds.) Design and systems: General applications of methodology, New Brunswick, NJ, USA, 1995, pp. 245-257.

[26] Dorst, K., Cross, N. "Creativity in the design process: co-evolution of problem-solution", Design Studies, 22(5), pp. 425-437, 2001. https://doi.org/10.1016/S0142-694X(01)00009-6

[27] Schön, D. A. "The Reflective Practitioner: How professionals think in action", Temple Smith, London, UK, 1983.

[28] Valkenburg, R., Dorst, K. "The reflective practice of design teams", Design Studies, 19(3), pp. 249-271, 1998. https://doi.org/10.1016/s0142-694x(98)00011-8 
[29] Hey, J. H. G., Joyce, C. K., Beckman, S. L. "Framing innovation: negotiating shared frames during early design phases", Journal of Design Research, 6(1/2), pp. 79-99, 2007. https://doi.org/10.1504/jdr.2007.015564

[30] Heylighen, A., Dong, A. "To empathise or not to empathise? Empathy and its limits in design", Design Studies, 65, pp. 107-124, 2019. https://doi.org/10.1016/j.destud.2019.10.007
[31] Osborn, A. F. "Applied Imagination: Principles and Procedures of Creative Thinking", Charles Scribner's Sons, New York, NY, USA, 1979.

[32] Knapp, J., Zeratsky, J., Kowitz, B. "Sprint: How to Solve Big Problems and Test New Ideas in Just Five Days", Simon \& Schuster, New York, NY, USA, 2016. 